\title{
A FORMAÇÃO PROFISSIONAL DO GESTOR ESCOLAR: ALICERCE PARA UMA POSTURA VERDADEIRAMENTE DEMOCRÁTICA
}

Ana Célia de Oliveira Paz ${ }^{1}$

RESUMO: Este artigo pretende analisar aspectos quanto à Gestão Democrática e as novas competências e aptidões cognitivo-atitudinais necessárias para que os gestores cumpram sua função nesta nova realidade socioeducativa determinante. Essa questão é referenciada à partir da renovação teórico-prática da administração educacional que enseja demandas para o gestor, tanto para sua atuação quanto para sua formação, preocupando-se com suas relações e com suas repercussões para a efetivação de uma administração escolar voltada para a democratização e participação de todos.

Palavras-chave: Gestão; Democracia; Gestor; Formação.

ABSTRACT: This article analyzes aspects and democratic management, and new skills and cognitive-attitudinal skills necessary for educators and managers to fulfill their special role in this new reality socio-importance. This issue is referenced from renewal theory and practice of educational administration which entails demands for the manager, both for his performance as for their training, worrying about their relationships and their implications for the effectiveness of a school administration turned to the democratization and participation.

Keywords: Management; Democracy; Manager; Training.

\section{A FORMAÇÃO INICIAL}

A atuação do gestor escolar é definida em função das necessidades e interesses do grupo social ao qual está inserida a escola administrada, e esse envolvimento competente é que direciona um sistema que deve promover a eficiência e a produtividade da escola democrática.

Pensar a formação do gestor escolar prescinde prioritariamente desvelar como ocorre a formação acadêmica inicial do professor, pois, entende-se que este profissional é formado inicialmente para ser professor, depois administrador, e é nesse sentido que percorre a análise dessa trajetória, perpassando pela formação inicial e continuada.

A formação do professor quer seja inicial ou continuada, inclusive a capacitação em serviço, tem se tornado uma das preocupações dos sistemas educacionais e constitui-se, segundo Nóvoa (1991, p. 68), num "eixo

\footnotetext{
${ }^{1}$ Mestrado em Educação pela Universidad de Alcalá (Espanha). Professora da Rede Pública de Ensino do Estado de Roraima. Contato: anaceliapaz2011@hotmail.com
} 
estratégico fundamental" de desenvolvimento de homens e organizações, que resulta na sua prática profissional, no contexto da sociedade.

A palavra formação, no sentido pedagógico, surge relacionada às questões militares em 1908, porém, é a partir dos anos 60 que passa a ser utilizada na educação com uma vasta gama de significados, abrangendo, tanto o curso (habilitação acadêmica), o sistema (o plano de formação dos formadores), quanto o processo (a formação como resultado). O termo formação, entendido como ensino, surge provavelmente da necessidade, que as pessoas sentem de atualizar os próprios conhecimentos constantemente, em razão das transformações sociais observadas, para as quais a escolarização formal já não consegue dar respostas somente com a estrutura institucional básica.

A formação em questão fica permeada pela associação entre a teoria e a prática, em que os envolvidos atendem aos objetivos dos diferentes níveis e modalidades de ensino e às características de cada fase do desenvolvimento daquele que está em formação, e que precisa continuar aprendendo e compreendendo os fundamentos científicos e tecnológicos dos processos produtivos e educacionais.

Autores como Behrens (1996), Brito e Purificação (2006), Nóvoa (1991), Almeida $(2002,2005)$, entre outros, defendem que a formação do professor não deve ser concebida como algo acabado, tendo em vista que há um conjunto de atividades que ocorre geralmente após a formação inicial e têm como objetivo o desenvolvimento do conhecimento, de competências e habilidades. É um processo que não se desenvolve à margem dos projetos das escolas, ao contrário, se apóia a implementação desses.

Estar em formação é considerar "[...] a valorização das formações informais, desde os processos de auto-formações até ao investimento educativo das situações profissionais e a articulação com os projetos educativos da escola [...]" (NÓVOA, 1991, p. 70), implica que não se ignore a forma como ocorre a aprendizagem, suas necessidades, motivações e pesquisas acerca de métodos inovadores.

Outro aspecto relevante na formação do professor é que não basta que ele queira implementar novas técnicas e métodos, é preciso que este alimente diuturnamente a sua vontade de construir algo novo e transformador, 
de compartilhar os momentos de dúvidas, questionamentos e incertezas, de encorajar o seu processo de reconstrução para novas práticas.

\section{A FORMAÇÃO CONTINUADA E A CONSTRUÇÃO DA PRÁXIS GESTORA}

A contemporaneidade revela que a dificuldade do professor em formação é reconstruir a sua práxis, tendo em vista que nem sempre ele está atuando em sala de aula, portanto, alheio à orientação e utilização das tecnologias como viés pedagógico, que difere da concepção de ensino e aprendizagem embasada na racionalidade técnica presente na atual estrutura curricular vigente.

É um processo que se desenvolve ao longo da carreira profissional, podendo se prolongar por toda uma vida, portanto, não se evidencia a dicotomia formação inicial e formação continuada, aplicada de diferentes formas, varia conforme a região e ou local do evento. Representa um desafio à pedagogia tradicional, porque significa introduzir mudanças no processo de ensino e aprendizagem, nos modos de estruturação e funcionamento da escola e nas relações com a comunidade.

$\mathrm{Na}$ formação inicial, os educadores adquirem competências e habilidades para desempenhar a atividade profissional, e a dinâmica da formação destes articula-se na dialética entre formação básica, formação inicial e formação continuada ou permanente, onde todas as etapas do processo formativo se complementam constituindo um mosaico de figura ampla e única.

A noção de formação continuada está relacionada à idéia de como se concebe a que lhe está subjacente, pois, vários são os fatores que diferenciam uma formação de outra, e podem estar relacionados à insuficiência da formação inicial, à disponibilidade de verbas, aos planejamentos ou ao quadro de formadores, tendo em vista a heterogeneidade na formação inicial.

A formação continuada é mais que formação, é também compreendida como formação permanente, pessoal e profissional, uma vez que cria espaços de discussões e investigação das questões educacionais experimentadas, que abre um canal de diálogo com as dificuldades cotidianas de ser educador num contexto social em veloz transformação. Visa à formação de sujeitos, pensa na 
mediatização dos conteúdos e no caminho percorrido pelo aprendiz para se apropriar das informações e construir / ampliar seus conhecimentos.

Nos Planos Nacional e Estadual de Educação, está previsto que as ações / atividades de formação continuada para os professores e gestores escolares da rede publica de ensino são coordenadas por programas específicos, dependendo do foco e linha de interesse da política pública estabelecida pelos respectivos sistemas, para os níveis de ensino as quais se destinam.

Esta formação, na maioria das vezes, ocorre por meio de cursos de pós-graduação lato-sensu e strictu-sensu, cursos de sensibilização, de extensão e ou aperfeiçoamento. Desenvolvem-se na própria instituição de ensino, universidades, centros ou núcleos de formação, e apresentam carga horária diferenciada presencial ou à distância, e podem ocorrer em fases distintas.

Dentre elas, as universidades federais, estaduais ou particulares viabilizam cursos de especialização lato sensu a professores graduados da rede pública estadual que atuam ou passam a atuar nos Estados como professores-gestores. Outra fase atende aos professores gestores das escolas estaduais que recebem uma formação continuada pelo Programa PROGESTÃO, facultado ao gestor escolar que tenha interesse.

Embora o Estado proporcione formação continuada para os profissionais da educação, é visível e necessário que o gestor escolar seja contemplado com uma formação específica, para poder atuar com eficiência na gestão e uso dos recursos tecnológicos em seus espaços de trabalho.

Evidencia-se a importância de se desenvolver programas de formação voltados para as especificidades do trabalho dos gestores, alicerçados na articulação entre as dimensões administrativas e pedagógicas. É preciso, que o gestor seja formado para perceber as diversas redes que compõem o conhecimento, é um processo que envolve muito mais do que "cumprir os dias letivos", já que na formação, ele também aprende a buscar os caminhos possíveis para desempenhar o seu papel. Esse desempenho requer comprometimento, liderança, capacidade administrativa, sobretudo, ações permeadas pela liberdade, autonomia, responsabilidade e atitudes democráticas. 
O conceito de Gestão Escolar, relativamente recente, é de extrema importância para que se tenha uma escola que atenda às atuais exigências da vida social: formar cidadãos e oferecer, ainda, a possibilidade de apreensão de competências e habilidades necessárias e facilitadoras da inserção social. Para fim de melhor entendimento, costuma-se classificar a gestão escolar em três áreas, que funcionam interligadas, de modo integrado ou sistêmico: Gestão Pedagógica, Gestão de Recursos Humanos e Gestão Administrativa. (SANTOS, 2006, p.130).

Assim, cabe ao gestor escolar assegurar que a escola realize sua missão: ser um local de educação, entendida como elaboração do conhecimento, aquisição de habilidades e formação de valores. O gestor deverá animar e articular a comunidade educativa na execução do projeto educacional, incrementando a gestão participativa da ação pedagógicoadministrativa, conduzindo a gestão em seus aspectos administrativo, econômico, jurídico e social. O gestor é o articulador/mediador entre escola e comunidade. Ele deve incentivar a participação, respeitando as pessoas e suas opiniões, o que se chama de gestão democrática.

O gestor escolar tem de se conscientizar de que ele, sozinho, não pode administrar todos os problemas da escola, assim, o caminho é a descentralização, isto é, o compartilhamento de responsabilidades com alunos, pais, professores e funcionários. Esse ápice evoca o envolvimento de todos os atores da comunidade escolar, e até mesmo local, no processo decisório.

As decisões tomadas coletiva e participativamente, é preciso pô-las em práticas. Para isso, a escola deve estar bem coordenada e administrada. Não se quer dizer com isso que o sucesso da escola reside unicamente na pessoa do gestor ou em uma estrutura administrativa autocrática na qual ele centraliza todas as decisões. Ao contrário, trata-se de entender o papel do gestor como líder cooperativo, alguém que consegue aglutinar as aspirações, os desejos, as expectativas da comunidade escolar e articular a adesão e a participação de todos os segmentos da escola na gestão em um projeto comum.

O diretor da unidade escolar não pode ater-se apenas às questões administrativas. "Como dirigente, cabe-Ihe ter uma visão de conjunto e uma atuação que apreenda a escola em seus aspectos pedagógicos, administrativos, financeiros e culturais" (LIBÂNEO, 2005, p.332). 
Um gestor bem preparado visualizará na Gestão Pedagógica o lado mais importante e significativo da gestão escolar, a partir dos seguintes procedimentos: cuida de gerir a área educativa, propriamente dita, da escola e da educação escolar; estabelece objetivos, gerais e específicos, para o ensino; define as linhas de atuação de acordo com os objetivos e o perfil da comunidade e dos alunos; propõe metas a serem atingidas; elabora os conteúdos curriculares; acompanha e avalia o rendimento das propostas pedagógicas, dos objetivos e o cumprimento das metas; e avalia o desempenho dos alunos, do corpo docente e da equipe escolar como um todo. É pois, o principal articulador da Gestão Pedagógica e o primeiro responsável pelo seu sucesso, auxiliado, nessa tarefa, pelos apoios pedagógicos.

A prática tem mostrado que o gestor é fundamental para dinamizar a construção coletiva do projeto, sua implantação e o acompanhamento e verificação da realização prática do que é teoricamente proposto. São "Profissionais competentes, líderes que tenham capacidade para coordenar esforços coletivos." (HENGEMUHLE, 2004, p. 191).

Um gestor bem preparado entende que sua função envolve atividades de mobilização, de motivação e de coordenação, saberá que dirigir uma escola implica colocar em ação os elementos do processo organizacional (planejamento, organização, avaliação), de forma integrada e articulada. Segundo Borges (2008, p. 83): "O gestor é a figura que deve possuir e liderança, no clima de organização da escola que pressupõe a liberdade de decidir no processo educativo e não nos gabinetes burocráticos".

A centralização das atividades e decisões educacionais por parte do gestor, provoca prejuízos irreparáveis para uma gestão. Isso, na maioria das vezes, decorre num acúmulo de responsabilidades e ações, que comprometem significativamente a qualidade da gestão. O caminho é a descentralização, isto é, o compartilhamento de responsabilidades com alunos, pais, professores e funcionários, o que está registrado por Paro, quando afirma que:

$\mathrm{Na}$ prática, entretanto, o que se dá é a mera rotinização e burocratização das atividades no interior da escola, e que nada contribui para a busca de maior eficiência na realização de seu fim educativo (PARO, 2008, p.130). 
O gestor escolar deve ser um líder pedagógico que apóia o estabelecimento das prioridades, avaliando, participando na elaboração de programas de ensino e de programas de desenvolvimento e capacitação de funcionários, incentivando a sua equipe a descobrir o que é necessário para dar um passo à frente, auxiliando os profissionais a melhor compreender a realidade educacional em que atuam, cooperando na solução de problemas pedagógicos, estimulando os docentes a debaterem em grupo, a refletirem sobre sua prática pedagógica e a experimentarem novas possibilidades, bem como enfatizar os resultados alcançados pelos alunos.

Entretanto, o que se constata são vários aspectos negativos referentes à função do gestor na escola pública, como o caráter burocrático no qual se encontra tão envolvido, a parte burocrática à qual são condicionadas, faltandoIhe, muitas vezes, tempo para cuidar da parte pedagógica, a colocação de sua função pedagógica em segundo plano, as relações de poder que se estabelecem, a sua importância como articulador pedagógico e mediador entre a escola e os segmentos da comunidade escolar e local, bem como a importância do exercício da liderança democrática tão necessária ao fortalecimento de sua prática gestora escolar.

Espera-se demonstrar como as funções mencionadas são essenciais ao gestor, caso o sistema educacional queira democratizar a gestão da escola pública e avançar na melhoria da qualidade do ensino. Conseqüentemente, essa abertura de modelo de gestão influenciará na qualidade de vida dos educandos no ambiente escolar, contribuindo para a efetiva participação cidadã na sociedade.

Observa-se que o impasse quanto a implantação ou não da gestão democrática, constitui um problema, que é tratado por muitos profissionais nos últimos anos, além de estarmos conscientes de algumas dificuldades que tem as escolas referente ao planejamento pedagógico, e levando em conta que o pedagogo principal da escola é o gestor, estando a responsabilidade maior em conduzir todo este processo voltada para sua pessoa.

É importante reafirmar a necessidade de elencar as qualidades do profissional da gestão associadas a uma boa formação inicial e continuada. A preparação desse profissional funciona como alicerce básico para um clima 
favorável à sua liderança e ao pleno exercício da democracia no ambiente escolar.

As instituições educacionais deveriam destinar recursos para uma política eficiente de preparação destinada aos gestores, com isso, evitar-se-iam transtornos muitas vezes causados por gestores despreparados ao sistema educacional.

É desejável que os candidatos à eleição ao cargo de gestor tenham formação profissional específica e competência técnica, incluindo liderança, capacidade de gestão e conhecimento de questões pedagógico-didáticas (LIBÂNEO, 2005, p. 332).

A gestão escolar na perspectiva da administração individual, da hierarquia e da fragmentação de tarefas vem perdendo seu espaço para a gestão democrática, entendida como compartilhamento de responsabilidades no contexto escolar. No entanto, sua inserção na organização e funcionamento das escolas configura-se como um grande desafio para os gestores que necessitam, na maioria das vezes, reconstruir suas concepções e práticas de gestão.

Nessa perspectiva, a gestão democrática passa a ser concebida sob o prisma de reconhecer a importância da participação de todos na organização e no planejamento do trabalho escolar, uma vez que o conceito de gestão está associado ao fortalecimento da democratização no processo pedagógico, à interação de todos nas decisões necessárias e na sua efetivação mediante compromisso coletivo.

Entende-se que o gestor constitui-se em um sujeito que assume o papel de coordenador de ações voltadas para objetivos coletivamente estabelecidos. Ou seja, aquele gestor, que por sua articulação e integração, desempenha conjuntamente com os demais indivíduos o trabalho escolar.

\section{CONCLUINDO...}

É importante refletir como a trajetória docente repercute na prática desse profissional, não mais chamado de especialista em educação, mas de gestor escolar. Acredita-se que há, inevitavelmente, influência das experiências pessoais e, concomitantemente, da formação inicial e continuada na prática gestora desenvolvida no cotidiano escolar. Por isso, conhecer a formação 
profissional dos gestores permite adentrar no campo dos sentidos e significados que a profissão representa para cada um. Nesse caso, destaca-se a importância da formação continuada, nesta pesquisa, como processo de autoformação crítico-reflexiva da e na prática gestora.

A continuidade da formação é indispensável para a profissionalização no atual contexto educacional e esse processo se constrói durante toda a carreira profissional, a partir da própria natureza dos saberes e dos fazeres humanos como práticas que se transformam constantemente. Desse modo, os saberes teóricos e práticos oriundos da trajetória docente passarão a compor, juntamente com os saberes para o desenvolvimento das atividades administrativas, os conhecimentos necessários para o trabalho na gestão.

Entende-se que a trajetória construtiva desse profissional necessita ser visualizada com um olhar reflexivo, no sentido de ser capaz de identificar as possíveis interferências que venham a determinar a sua prática gestora. Percebe-se que, na maioria das vezes, o gestor escolar direciona a sua prática a partir das concepções de gestão internalizadas ao longo de sua trajetória. Nessa perspectiva, Mizukami (2002, p. 48) aponta que "[...] os conhecimentos, as crenças e as metas são elementos fundamentais na determinação do que fazem e de por que o fazem". Assim, a gestão escolar assume diferentes perspectivas conforme a concepção que os gestores têm das finalidades sociais e políticas da educação em relação à sociedade e à formação discente.

\section{REFERÊNCIAS BIBLIOGRÁFICAS}

NÓVOA, Antonio. Formação contínua professores: realidades e perspectivas. Aveiro: Universidade de Aveiro, 1991.

ALMEIDA, M. E. B de. Gestão de tecnologias na escola: possibilidades de uma prática democrática. In: SALTO para o Futuro. Série Integração de tecnologias, linguagens e representações. Rio de Janeiro: TV Escola, SEEDMEC, 2005.

HENGEMUHLE, Adelar. Gestão de ensino e práticas pedagógicas. Petrópolis, RJ: Vozes, 2004.

BORGES, Heloisa da Silva. Organização do Trabalho Pedagógico e Gestão Escolar. Manaus: Edições UEA Ed. Valer, 2008. 
LIBANEO, José Carlos. Educação escolar: políticas, estruturas e organização. $2^{a}$ ed. São Paulo: Cortez, 2005.

PARO, Vitor Henrique. Administração escolar: introdução crítica. $15^{a}$ ed. São Paulo: Cortez, 2008.

MIZUKAMI, M. G. N. (et al.). Escola e aprendizagem da docência: processos de investigação e formação. São Carlos: UFSCar, 2002.

SANTOS, Maria Elizabete dos. Função do Gestor na Escola Publica. Revista de Divulgação técnico-cientifica do ICPG, v. 3, n.9, jul./dez. 2006.

BEHRENS, M. A. O paradigma da complexidade na formação e no desenvolvimento profissional de professores universitários. Porto Alegre: Educação, 2007. (ano XXX, n. 3).

BRITO, Glaucia da Silva; PURIFICAÇÃO, Ivonélia da. Educação e novas tecnologias: um repensar. Curitiba: Ibpex, 2006.

BRITO, G. S. Tecnologias da Comunicação e Informação: controle e descontrole. Inclusão digital do profissional professor: entendendo o conceito de tecnologia. In: $30^{\circ}$ ENCONTRO ANUAL DA ANPOCS, 24-28 de outubro de 2006. 